\title{
REPORT OF CLINICAL TRIAL WITH ETISUL
}

\author{
By Dr. Y. F. ChaO \\ Mackay Memorial Hospital, Taipei, Taiwan
}

\section{Name of Drug}

Etisul or Diethyl Dithiolisophthalate.

\section{Chemistry and Composition}

In 1950, Del Pianto claimed that a mixture of certain thiol compounds prevented the development of tuberculosis in infected guinea-pigs and in 1956 DAviEs et al. traced the active principle to ethyl mercaptan and compounds capable of forming it. This property was limited to the ethyl homologue and was evident almost solely in vivo. They concluded that a metabolite of ethyl mercaptan was the ultimate active agent and suggested thiol esters as the most useful group of compounds for the treatment of human disease.

DAviEs and DrIVER (1957) chose diethyl dithiolisophthalate (Etisul) as the most promising for therapeutic use. It has an antituberculous effect in mice comparable to that of isonicotinic acid hydrazide and streptomycin and was most effective when injected subcutaneously or applied to the skin. It has since been added to the list of anti-leprotic drugs.

The chemical structure of Etisul is as follows:-

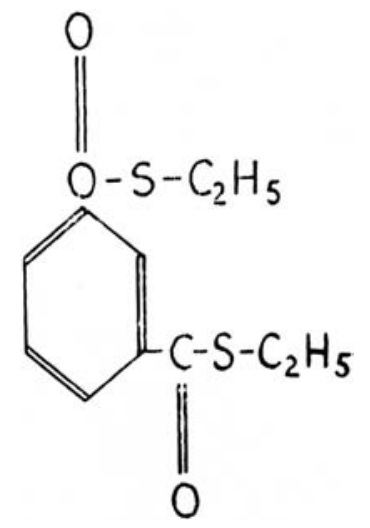

A product of Imperial Chemical Industries Ltd., Pharmaceuticals Division, England, Etisul is in the form of a soft cream, light yellow in colour with a garlic-like odour, containing diethyl dithiolisoph thalate $(72 \mathrm{w} / \mathrm{w})$, and perfumed with aromatic substances. It is packed in $5 \mathrm{~g}$. tubes.

\section{Efficacy and Versatility of Etisul}

Specifically indicated for various types of leprosy, Etisul is of 
particular value in the early stages. Its use hastens recovery and shortens the course of treatment. This is evidenced by the speedy decrease of the nodules and skin lesions, and the rapid marked reduction of a high bacterial index to negative.

Etisul can be applied safely by all persons irrespective of age and sex, and is free of contra-indications. When used together with other anti-leprotic drugs, such as DDS, Ciba 1906, Sulphetrone, etc., Etisul is not only very safe and free from any side effects, but also helps to attain a higher level of therapeutic efficacy.

In the case of lepra-reactive patients, Etisul either prevents same or reduces the severity. The onset of leprosy and its initialsymptoms consist of the nodules, pigmentation or tubercles of the skin. By applying Etisul directly to the skin, its therapeutic efficacy is demonstrated by the speedy reduction of the external symptoms, which results in a favourable psychological effect on the patients.

\section{Dosage and Mode of Application}

Approximately $2.5 \mathrm{~g}$. of Etisul was applied to the skin, 2 or 3 times per week. After application the ointment was massaged into the skin for duration of 20 minutes to hasten the dermal absorption. The massaged area was then exposed to the air for a period of 3 hours after which the area was washed with soap and water to remove the odour of the medicine.

\section{Clinical Trials}

(a) Eight cases were selected for clinical trial of Etisul in combination with sulphone drug or Ciba 1906 during the period of January to June 1960. These cases had previously received sulphones or Ciba 1906 for a period of at least 6 months and were selected because no improvement on these medications, their intolerance to optimal dosage of sulphones or due to lepra reactions.

(b) Classification: 4 lepromatous and 4 tuberculoid, one female tuberculoid patient and the remainder were males.

(c) Results: Lepromatous: Marked improvement, 3-marked improvement of skin lesions with a decrease in the bacterial index from severe to mild positive. One of these cases had far advanced lepromatous leprosy for more than 14 years and shown no improvement after receiving 2 years treatment according to the DDS regulation.

Moderate Improvement: 1-a young man with frequent lepra reaction who was intolerant to DDS and received Sulphetrone $3.0 \mathrm{gm}$. weekly. His bacterial index decreased from 4.5 to 3.8 and his lepra reaction subsided one month after the trial with Etisul.

Tuberculoid: Marked Improvement, 1-resolution of almost of his major tuberculoid macules. 
Mild Improvement: 2 general improvement of skin lesions. One of these was a patient who had reactional tuberculoid leprosy. He was given Ciba 1906 because of severe toxicity to sulphone preparations. His improvement was mild with disappearance of the lepra reaction.

Periodical laboratory routine examinations including blood, urine and stool for the above 8 patient were performed during the past 6 months' trial of Etisul but none of them were found positive for toxic manifestation.

\section{Conclusion}

It has been noted that this drug has not produced a toxic reaction even in the two patients that had previous toxic reaction to the sulphones. It was also noted that there was change in the staining properties of the bacilli and rapid fall in the bacterial index with subsequent resolution of the lesions.

It can readily be used in conjunction with DDS, Sulphetrone and Ciba 1906. When combined in this way resolution was rapid and no drug resistance was noted. The most striking case was that of the man who was resistant to DDS treatment for a period of 2 years who revealed marked improvement and complete recovery from lepra reaction when his treatment was combined with Etisul.

\section{Acknowledgements}

We would like to thank the Imperial Chemical Industries Pharmaceutical Division, for their contribution of Etisul in this clinical trial.

Ref erences

1. Davey, T. F. and Hogerzeil, L. (1959) Leprosy Review 30, 61.

2. DaveY, T. F. (1959) Leprosy Review 30, 141. 